the question of divesting the natural parents of their rights is carried over into the period of time which ought to be devoted solely to inquiring into the suitability of the new parents. As a result all parties are racked by uncertainty. The report acknowledges the psychological need for some ceremony to attend the decision in favour of adoption, and this would be met if there were two court ceremonies instead of one. At the first ceremony the court would determine any conflict between natural parents, or would examine the reality of a natural parent's decision, or would merely provide the panoply to assist the natural parent in seeing the decision as irrevocable. While the court should and will recognize that a helpless child needs special assistance he does not need special overriding rights at this stage as against his natural parents. But at the second stage-the selection of adoptive parents-the interests of the child should be the only consideration. The separation into stages would assist in clearer thought.

The problems of adoption are particularly difficult. Social workers' theories are still being evolved and they lack consistency. The practice of the courts also lacks consistency, and the necessary requirement of hearings in secret does not assist in the development of a nationally consistent practice. Above all there looms the meanness of the Treasury, apparent in any area that is not politically explosive. The adoption societies need money from Treasury funds, the courts need money to provide facilities befitting the dignity and importance of the decisions taken. At present a child's life is decided in places where a businessman would decline to decide what to eat for lunch. Clearly an authoritative commission is required to examine all aspects of the law and the practice of adoption procedures in detail, following the pointers provided by the societies' report. A new and radically altered Adoption Act is urgently needed.

\section{Why Not Child Visitors?}

A recent survey of obstetric patients in Adelaide has shown that there are advantages in permitting children to visit their mothers in hospital. ${ }^{1}$ Of the mothers answering a questionary $91 \%$ approved the practice and only $7 \%$ disapproved ; the majority of those who disapproved were primipara. About half the primipara gave qualified approval only; the reservations made included an absolute restriction on child visitors below a minimum age (the minimum was variously given as from 3 to 10 years), restrictions on the time and duration of visiting, and comments on rowdy behaviour in the children. During the course of the survey child visitors were allowed in the hospital, in which the babies spend much of the time in the ward with their mothers, and over the trial period there were no ill effects on the general welfare of the patients and no increase in the incidence of infection or illness in babies or mothers. Visits by sick children or those suffering from colds or boils or any rash were not permitted.

In the past several objections have been raised to visiting by children. There may be complaints that their presence and sometimes their noisy behaviour is disturbing to the staff

\footnotetext{
- Report to the Home Office in Difficulties Arising from the Adoption Act, 1958, Standing Conference of Societies Registered for Adoption. London, 1968.
}

and to other patients. It is also said that visiting may unsettle the mother and also the children, who may have resigned themselves to the situation-but "resignation" on the part of children may be a sign of stress. ${ }^{2}$ The principal objection to visiting by children is the risk of infection to mother and baby, and the danger has been stressed by B. Eton. ${ }^{3}$

Opportunities for contact between mother and babies and infected persons are multiplied once visitors, be they children or adults, are admitted. However, even the problem of the permissible degree of contact between staff, mothers, and babies who are not at special risk of infection has not yet been resolved, and there are conflicting reports of the effects of divergent practices on the incidence of sepsis. Practice in maternity units on contact with newborn babies varies from strict isolation of babies in nurseries to which no visitors are admitted and where even the attending physician can see his patient only in surgical dress, to permissive systems where the newborn are allowed out of the hospital to be christened in a nearby church. Between these practices lie systems in which the babies room with their mothers, often in multiple bedded wards. Although L. Frappier-Davignon and his colleagues ${ }^{4}$ showed that the incidence of neonatal infection was lowest in babies fully isolated in separate nursery accommodation, J. K. Burden ${ }^{5}$ found a higher incidence of infection in a small series of such babies than in those who "roomed in." V. D. Pleuckhahn ${ }^{6}$ noted a rapid decrease in the incidence of staphylococcal disease after removal of infants from communal nurseries and adoption of a "rooming in" procedure. Babies are as likely to pick up staphylococcal infections ${ }^{7}$ from nurses and doctors as from visitors. ${ }^{8}$

Mothers, too, may be exposed to dangerous sources of infection from visitors. The incidence of scarlet fever, though low, is not negligible and reaches its peak between the ages of 4 and 10. Over 11,000 cases were reported to the Registrar General for England and Wales in 1966. The incidence of streptococcal tonsillitis is not recorded, but small children are notoriously prone to upper respiratory tract infections including bacterial sore throats. It seems that children are more infective than adults, for J. E. Gordon ${ }^{10}$ states that children under five years are responsible for about 11 times as many secondary cases as are patients aged 15 years or older; A. F. Coburn and R. H. Pauli ${ }^{11}$ also found children more infective than adults. So it seems that the risk of infection from children is greater than from adults.

This risk must be weighed against the very great benefits that may accrue to individual children and mothers if visiting is allowed. Are we prepared, in order to prevent what are often trivial and self-limiting infections, to expose some children to the greater risk of mental illness ${ }^{2}$ ? Clearly children who are ill, or who come from homes or environ-

1 Craven, D. M., Aust. Paediat. F., 1967, 3, 248.

" Cook, P. S., N.Z. med. F., 1962, 61, 605.

s Eton, B., Brit. med. ₹., 1966, 2, 304.

- Frappier-Davignon, L., Frappier, A., and St.-Pierre, J., Canad. med. Ass. F., 1959, 81, 531 .

- Burden, J. K., Med. 7. Aust., 1959, 1, 520.

- Plueckhahn, V. D., Brit. med. F., 1961, 2, 779. Personal communicaion, 1968.

' Lowbury, E. J. L., in Infection in Hospitals, ed. R. E. O. Williams and R. A. Shooter, 1963, p. 251. Oxford.

- Grün, L., in Infection in Hospitals, ed. R. E. O. Williams and R. A Shooter, 1963, p. 95. Oxford.

- Registrar General's Statistical Review of England and Wales, Part (1966) Table 30, 1968. H.M.S.O.

10 Gordon, J. E., Lancet, 1940, 1, 511.

1 Coburn, A. F., and Pauli, R. H., f. exp. Med., 1941, 73, 551

"Vartan, K., Brit. med. F., 1966, 2, 890. 
ments where there are known cases of infectious disease such as scarlet fever, should not be allowed to visit ; and the number of children in any ward at one time must be limited. Newborn babies should not be handled, and in many cases need not be shown to the child visitors at all. Only children of the mothers in the unit should be allowed to visit.

Despite the theoretical risks there is little evidence that visiting by children increases the incidence of infection, though few surveys have been made. P. S. Cook ${ }^{2}$ cited experience of a scheme whereby the mother's own children were allowed to visit; mothers and children were much happier, the staff derived satisfaction from seeing the obviously beneficial effects on the families, and there was no indication that the infection rate was increased. Pleuckhahn ${ }^{6}$ found no evidence of increased infection in the two-year period over which child visitors have been permitted at Geelong Hospital, Victoria. K. Vartan ${ }^{12}$ reported that no serious complications had arisen in five years' experience of child visiting. On balance it seems that visiting by children is not accompanied by a demonstrable rise in the sepsis rate ; and other objections such as inconvenience to the staff or complaints of noisy behaviour in the children can be overcome by good organization.

\section{Acute Optic Neuritis}

Acute optic neuritis is characterized by the onset of blurred vision, usually in one eye. The visual disturbance usually takes the form of a unilateral central scotoma, which gradually enlarges over a few days, persists for one to three weeks, and then gradually improves. The pupil on the affected side is usually dilated and its contraction to direct light is illsustained (Kestenbaum's sign). ${ }^{12}$

Over $80 \%$ of the patients with acute optic neuritis are between 20 and 50 years old, ${ }^{3}$ and the condition is twice as common in women as in men. The presenting symptom may be pain or tenderness in the eye, which is made worse by movement of the globe, particularly in a lateral direction. The pain is usually situated in or around the eye, the supraorbital region, or the frontal area, and it persists for several days and occasionally for as long as two or three weeks.

If no abnormality of the optic fundus is seen the condition is called "retrobulbar neuritis," but in nearly a quarter of cases there is some pinkness of the disc with blurring of its margins ("papillitis"). ${ }^{3}$ Sometimes the oedema of the disc is so severe that it resembles papilloedema. The oedema may spread to affect the retina and there may even be associated haemorrhages, though these are usually close to the disc margin (" neuroretinitis").

The differential diagnosis of unilateral central scotoma is sometimes difficult. Retinal vascular occlusion produces a more sudden onset, and the narrowed arteries (if the occlusion is arterial) or congested veins and haemorrhages (if venous)

\footnotetext{
Ruse F. C., Postgrad. med. F., 1964, 40, 692.
}

2 Rose, F. C., Proc. roy. Soc. Med., 1968, 61, 122.

sradley, W. G., and Whitty, C. W. M., F. Neurol. Neurosurg. Psychiat. $1967,30,531$.

Bıadley, W. G., and Whitty, C. W. M., f. Neurol. Neurosurg. Psychiat., $1968,31,10$.

- Rawson, M. D., Liversedge L. A., and Goldfast, G., Lancet, 1966, 2, 1344 . are easily seen. Vascular occlusion affecting the optic disc alone and temporal arteritis occur in an older age group. Compression of the optic nerve has a slower onset and the central scotoma eventually affects the periphery of the visual field as well. Toxic amblyopia (for example, due to tobacco) occurs in men after middle age, and the scotomata are bilateral and centrocaecal. Leber's hereditary optic atrophy is also bilateral, $80 \%$ of cases occurring in males usually between the ages of 10 and 30 ; there is a family history of the condition, and recovery to normal vision is rare.

In more than three-quarters of the cases of acute optic neuritis the visual acuity returns to normal or near normal within six months. ${ }^{3}$ Following recovery the patient may complain that colours appear much paler, but visual acuity is little affected and the only residual abnormality, which is not invariable, is temporal pallor of the optic disc.

Although many causes have been suggested for acute optic neuritis, the only definite one in some patients is multiple sclerosis. Of these patients $10 \%$ have evidence of demyelination elsewhere and about half will be found to have further episodes of demyelination if they are followed up for up to 20 years. Acute optic neuritis occurs in about half the patients with multiple sclerosis. In those patients who show no other signs of demyelination sinusitis has been suggested as a possible aetiological factor, but there is little evidence in favour of this."

Of the many remedies suggested, controlled trials showed that, though corticotrophin may speed recovery, it has no effect on either the eventual recovery of vision ${ }^{5}$ or on further attacks of demyelination.

\section{Disorders of Tyrosine Metabolism}

During the last decade reports have appeared with increasing frequency describing clinical disorders in children associated with abnormalities of tyrosine metabolism. The reader may easily become confused by them, since there is no general agreement on terminology.

Tyrosinosis (also called hereditary tyrosinaemia, tyrosinaemia, hepato-renal dysfunction) is a disorder first described by $\mathrm{K}$. Sakai and T. Kitagawa in $1957^{1}$ in a Japanese infant, and subsequently by others. ${ }^{2-4}$ It is inherited probably as an autosomal recessive condition. The syndrome includes cirrhosis of the liver and renal tubular defects, with vitaminD-resistant rickets, and is associated with a moderate rise in the serum tyrosine up to about $10 \mathrm{mg}$. per $100 \mathrm{ml}$. (normal up to $3 \mathrm{mg}$., depending on age and method) and tyrosyluria (which denotes excretion of tyrosine and its metabolites). A number of infants, particularly of French-Canadian origin, have had methioninaemia in addition ${ }^{5}$; these infants had a foul smell. The condition is associated with a deficiency of $p$-hydroxyphenylpyruvic acid oxidase ( $p$-H.P.P.A. oxidase) in the liver. ${ }^{6-9}$ The prognosis for untreated patients is poor. In some of them liver failure and death occur within the first 8 months or so of life, particularly if methioninaemia is present. ${ }^{4}$ Recent reports ${ }^{10-13}$ on the treatment of the condition by a diet low in tyrosine and phenylalanine, and in methionine too if necessary, are so encouraging that it should always be attempted in a properly diagnosed patient. Adequate facilities for controlling the diet and carrying out laboratory tests are essential. 